Sulbactam với tỷ lê $46,9 \%$ và $54,7 \%$ và Cotrimoxazole $71,4 \%$. Với nhóm Cefalosporin các thế hệ thì $E$. coli đã đề kháng lại với tỷ lệ khá cao như đề kháng với Cefazolin là 73,1\%, Ceftriazone là $51,6 \%$ và Cefotaxim $53,7 \%$.

K. pneumoniae đề kháng ít với các nhóm kháng sinh Cefalosporin, Quinolon. Tuy nhiên lại đề kháng cao với Co-trimoxazole với tỷ lệ 71,4\%.

\section{TÀI LIÊU THAM KHẢO}

1. Đoàn Thị Hồng Hanh (2011), Nghiên cứu khả năng sinh beta-lactamase phổ rộng của các VK Gram âm phân lâp đước tai Bênh viên Viêt Nam Thụy Điển (Uông Bí), Luận án Tiến sỹ Y học, Học viên Quân y, tr 215.

2. Mai Lan Hương (2011), "Căn nguyên gây nhiễm trùng huyết và mức độ kháng kháng sinh của vi khuẩn phân lâp tai Bênh viên Bach Mai từ 01/01/2011 đến 30/06/2011", Luận vắn Thạc sỹ y hoc, Đai hoc Y Hà Nôi, tr.124.

3. Trần Thúy Liên (2015), "Nghiên cứu mức độ kháng kháng sinh và phát hiện sư có măt của gen New Delhi metallo beta-lactamase 1 ở các chủng Escherichia coli và Klebsiella pneumoniae gây bệnh tai Bênh viên TWQĐ 108 (6/2014 - 6/2015)", Luân văn Thăc sỹ் Y học, Học viên Quân y, tr 152.

4. Lê Văn Nam, Trân Viết Tiến và Hoàng Vũ
Hùng (2014), "Nghiên cứu mức độ nhạy cảm kháng sinh trên các chủng $E$. coli phân lâp từ máu bênh nhân nhiễm khuẩn huyết điều trị tại Bênh viện Bệnh Nhiệt Đới Trung Ương", Tạp chí Y dược hoc quân sứ, 3, 97-101.

5. Trân Thanh Nga, Nguyễn Thanh Bảo, Cão Minh Nga (2015), "Tác nhân vi khuẩn gây nhiễm khuẩn huyêt và sự đề kháng kháng sinh tại khoa hồi sức cấp cứu Bểnh viện Chợ Rẩy" ${ }^{\prime \prime}$ Tạp chí Y học Thành Phố Hồ Chí Minh, 19 (1), 105-106.

6. Nguyễn Phương Kiệt, Richart K. Root, Richart Jacobs (1995), "Nhiếm trùng máu và sốc nhiểm trùng", Các nguyên lý y học nội khoa., Nhà xuất bản y hoc, 118-127.

7. Hoàng Tihị Thanh Thủy, Phạm Văn Ca, Nguyễn Vũ Trung và cộng sự (2013), "Căn nguyên vi khuẩn gây nhiếm khuẩn huyết tai Bênh viên Bênh Nhiệt Đới Trung Ương năm 2012", Tạp chí Y học Viêt Nam, 5 (2), 89-92.

8. Trần Viết Tiến, Nguyễn Thị Phương (2018), "Nghiên cứu đặc điếm lâm sàng, cận lâm sàng và tình trang kháng kháng sinh của vi khuẩn Klebsiella ở bệnh nhân nhiếm khuẩn huyết (01-2015 đến 62016)", Tap chí Y dược hoc quân sự, 7, 52-59..

9. De Kraker MEA. et ai (2012), The changing epidemiology of bacteremia in Europe: trends from the European Antimicrobial Resistance Surveillance System. Clin Microbiol Infect, 19 (9), 860-868.

\title{
NGHIÊN CỨU GIÁ TRI TIÊN LƯỢNG CỦA THANG ĐIỂM PAASH VÀ CÁC YẾU TỐ NGUY Cơ LIÊN QUAN TớI KẾT CỤC CHỨC NĂNG THẦN KINH XẤU Ở BÊ̂NH NHÂN CHẢY MÁU DƯớI NHÊ̂N DO VỠ PHİNH ĐộNG MẠCH NÃO
}

\section{TÓM TẮT}

Mục tiêu: Phân tích mối liên quan giữa thang điểm PAASH và kết cuc chức năng thần kinh (theo thang điểm Rankin sửa đổi và một số yếu tố liên quan tới kết cuc chức năng thần kinh bất lợi) tai thời điểm 1 tháng ở bệnh nhân chảy máu dưới nhện do vỡ phình mach não. Đối tượng và phương pháp nghiên cứu: Nghiên cứu mố tả tiến cứu 71 bệnh nhân được chẩn đoán xuất huyết dưới nhên do vỡ phình đônng mạch não được điều trị tại Bệnh viện Việt Đức từ tháng 8 năm 2019 tới tháng 8 năm 2020. Kết quả: PAASHscore có mối liên quan đồng biến với mRS=4-6 tai thời điểm 1 tháng với $\mathrm{OR}=4,423$ (CI 95\%: 2,378$4,927)$ có ý nghĩa thống kê với $p<0,001, O R$ tăng dần tữ 2,24 đến 52,0 ở mức độ nặng theo PAASH tữ mức II đến IV với $p<0,005 ; A U R O C=0,829$ giữa PAASHscore với $m R S=4-6$, điểm cut-off PAASHscore = 2,5 có độ nhạy $72,9 \%$ và độ đặc hiệu $86,6 \%$;

*Bênh viên Viêt Đức

Chịu trách nhiệm chính: Ngô Mạnh Hùng

Email: ngomanhhung2000@gmail.com

Ngày nhận bài: 18.11.2020

Ngày phản biên khoa hoc: 29.12.2020

Ngày duyệt bài: 8.01.2021 WFNSscore co môi liên quan đông biên với mRS $=4-6$
tai thời điểm 1 tháng với $\mathrm{OR}=2,47$ (CI 95\%: $1,899-$ $3,231)$ có ý nghĩa thống kê với $p<0,001$, ở độ IV và V theo WFNSscore cho $\mathrm{OR}=12,256$ và $71,0(\mathrm{p}<0,001)$; $A U R O C=0,821$ giữa WFNSscore và $m R S=4-6$, điểm cut-off WFNSscore $=3,5$ có độ nhạy $78 \%$ và độ đặc hiệu 79,5\%. Kết luận: thang điểm PAASH có giá trị tốt trong việc dự đoán kết cục chức năng tại thời điểm 1 tháng sau khởi phát của bệnh nhân xuất huyết dưới nhện do võ phình mạch não và có giá trị tương đương với thang điểm WFNS.

\section{SUMMARY}

STUDY OF THE PROGNOSTIC VALUES OF THE PAASH SCALE AND THE RISK FACTORS ASSOCIATED WITH THE OUTCOME OF POOR NEUROLOGICAL FUNCTION IN PATIENTS WITH SUBARACHNOID HEMORRHAGE DUE TO RUPTURE OF CEREBRAL ANEURYSM

Objective: To analyze the relationship between the PAASH score and neurological function outcome (modified Rankin scale) a number of risk-factors in relation to an adverse neurologic function at 1 month in patients with subarachnoid hemorrhage due to rupture of cerebral aneurysm. Patients and 
methods: A prospective, decribre study of 71 patients diagnosed with subarachnoid hemorrhage due to rupture of cerebral aneurysm were treated at Viet Duc Hospital from August 2019 to August 2020. Results: PAASHscore has a positive relationship with $\mathrm{mRS}=4$ 6 at the time of 1 month with OR $=4,423$ (95\% CI: $2,378-4,927$ ) having statistical significance with $p$ $<0.001$, OR gradually increasing from 2.24 to 52.0 in severe degree according to PAASH level II to IV with $p$ $<0.005$; AUROC $=0.829$ between PAASHscore and $\mathrm{mRS}=4-6$, cut-off point PAASHscore $=2.5$ has a sensitivity of $72.9 \%$ and a specificity of $86.6 \%$; WFNSscore has a positive correlation with mRS $=4-6$ at 1 month with OR $=2.47$ (95\% CI: 1,899-3,231) statistically significant with $\mathrm{p}<0.001$, at degrees IV and $\mathrm{V}$ according to WFNSscore for OR $=12,256$ and $71,0(p<0.001)$; AUROC $=0.821$ between WFNSscore and $\mathrm{mRS}=4-6$, the cut-off point WFNSscore $=3.5$ had a sensitivity of $78 \%$ and a specificity of $79.5 \%$. Conclusion: The PAASH scale is of good value in predicting functional outcomes 1 month after onset of patients with cerebral aneurysm rupture and is equivalent to the WFNS score.

\section{I. ĐẶT VẤN ĐỀ}

Xuất huyết dưới nhện (XHDN) là tình trạng chảy máu trong khoang giữa màng nhện và màng mềm chiếm sấp xỉ 50\% các trường hợp xuất huyết não. Nguyên nhân XHDN có thể do chấn thương hoặc không do chấn thương. Hầu hết các trường hợp XHDN không do chấn thương gây ra bởi vỡ phình động mạch. Đây là tình huống lâm sàng nghiêm trọng với tỉ lệ tử vong và tàn phế cao. Tử vong và tàn tật sau XHDN do võ phình động mạch thường có liên quan đến mức độ nghiêm trọng ban đầu của xuất huyết. Một số thang điểm đánh giá tiên lượng thường được sử dụng là thang điểm của hiệp hội phẫu thuật thần kinh thế giới (The World Federation of Neurological Surgeons (WFNS) Committee scale) [1], thang điểm Hunt-Hess [2]. Tuy nhiên các việc đánh giá các khiếm khuyết thần kinh của các thang điểm trên khó đánh giá chính xác ở những người thiếu kinh nghiệm và khác nhau giữa những người đánh giá.

Thang điểm PAASH được phát triển dựa trên thang điểm Glasgow Coma Scale (GCS) với ưu điểm đơn giản, dễ thực hiện. Nghiên cứu của
Annemarie W thực hiện trên 537 bệnh nhân chỉ ra rằng thang điểm PAASH và thang điểm WFNS đều cho thấy giá trị trong việc tiên lượng kết cục chức năng thần kinh [3]. Tuy nhiên thang điểm PAASH hiện nay vẫn chưa được áp dụng nhiều tại Việt Nam. Vì vậy chúng tôi làm nghiên cứu này với mục tiêu: Phân tích mối liên quan giữa thang điểm PAASH và kết cục chức năng thần kinh (theo thang điểm Rankin sưa đổi) tại thời điểm 1 tháng ở bệnh nhân chảy máu dưới nhện do võ phinh mach não.

\section{II. ĐỐI TƯỢNG VÀ PHƯƠNG PHÁP NGHIÊN CỨU}

1. Đối tượng nghiên cứu: Bệnh nhân chảy máu dưới nhện do vỡ phình động mạch não được điều trị tại Bệnh viện Việt Đức (trung tâm PTTK, trung tâm gây mể hồi sức và trung tâm chẩn đoán hình ảnh) từ tháng 8 năm 2019 tới tháng 8 năm 2020.

Tiêu chuẩn lựa chọn:

- Tuổi $\geq 18$ (năm).

- Triệu chứng khởi phát xuất hiện trong vòng 4 ngày trước khi được tuyển chọn vào nghiên cứu.

- Được chẩn đoán xuất huyết dưới nhên do võ phình động mạch não theo Hướng dẫn điều trị xuất huyết dưới nhện do võ̃ phình động mạch của tổ chức đột quy châu Âu 2012, bao gồm:

○ Xác định xuất huyết dưới nhện trên phim chụp cắt lớp vi tính sọ não (hoặc sự hiện diện của hồng câu và/hoặc sắc tố vàng [xanthochromia] trong dịch não tủy)

o Phình động mạch não được xác định trên phim chụp cắt lớp vi tính đa dãy não và mạch não hoặc trên phim chụp mạch não số hóa xóa nền.

Tiêu chuẩn loại trừ:

- Không đánh giá được điểm hôn mê Glasgow thời điểm nhập viện (ví dụ: bệnh nhân đã được đặt ống nội khí quản...).

- Không đánh giá được kết quả chức năng thần kinh (theo thang điểm Rankin sửa đổi) thời điểm 1 tháng kể từ khi khởi phát triệu chứng.

- Bệnh nhân và/hoặc người đại diện hợp pháp cho người bệnh không đồng ý tham gia nghiên cứu.

2. Phương pháp nghiên cứu: Mô tả tiến cứu.

\section{KẾT QUẢ NGHIÊN CỨU}

1.Mối liên quan giữa điểm PAASH với điểm $m R S=4-6$ tại thời điểm 1 tháng

Bảng 1.1. Mối liến quan giữa điểm PAASH với điếm $m R S=4-6$ tại thời điếm 1 tháng

\begin{tabular}{|c|c|c|c|c|c|}
\hline & \multirow{2}{*}{$\begin{array}{l}\text { Tân } \\
\text { suất }\end{array}$} & \multirow{2}{*}{$\begin{array}{l}\text { Tỷ số chênh } \\
\text { (OR) }\end{array}$} & \multicolumn{2}{|c|}{ KTC 95\% } & \multirow[b]{2}{*}{$\mathbf{p}$} \\
\hline & & & Nhỏ nhất & Lớn nhất & \\
\hline PAASH score & 71 & 3,423 & 2,378 & 4,927 & $<0,001$ \\
\hline \multicolumn{6}{|c|}{ Phân loại mức độ nặng theo PAASH: } \\
\hline Độ I & 33 & - & - & - & - \\
\hline Độ II & 13 & 2,240 & 0,755 & 6,646 & $<0,001$ \\
\hline
\end{tabular}


VIETNAM MEDICAL JOURNAL N²2 - JANUARY - 2021

\begin{tabular}{|c|c|c|c|c|c|}
\hline Độ III & 12 & 15,200 & 5,412 & 42,692 & $<\mathbf{0 , 0 0 1}$ \\
\hline Độ IV & 10 & 40,000 & 11,147 & 143,541 & $<\mathbf{0 , 0 0 1}$ \\
\hline Độ V & 3 & 52,000 & 3,214 & 318,619 & $\mathbf{0 , 0 0 3}$ \\
\hline
\end{tabular}

Nhận xét: Mức độ nặng phân loại theo thang điểm PAASH càng tăng thì tỷ lệ gặp kết cục bất lợi càng lớn

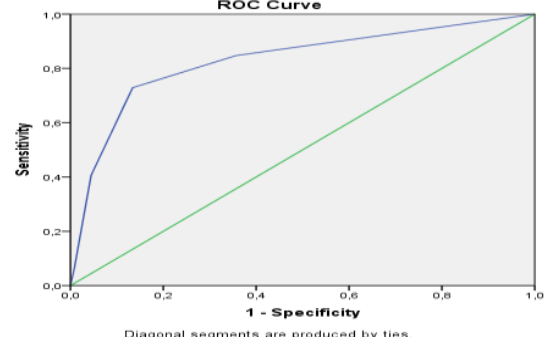

Biểu đồ 1.1. Đường cong AUROC giữa điểm PAASH với $m R S=4-6$

\begin{tabular}{|l|c|c|c|}
\hline \multirow{2}{*}{ Biến số } & \multirow{2}{*}{$\begin{array}{c}\text { Diện tích } \\
\text { dưới đường } \\
\text { cong }\end{array}$} & \multicolumn{2}{|c|}{ KTC 95\% } \\
\cline { 3 - 4 } & Nhỏ nhất & Lớn nhất \\
\hline PAASH & 0,829 & 0,759 & 0,899 \\
\hline
\end{tabular}

Toa đô của đường cong PAASH

\begin{tabular}{|c|c|c|}
\hline $\begin{array}{c}\text { Dương tính nếu } \\
\text { lớn hơn giá trị }\end{array}$ & $\begin{array}{c}\text { Độ } \\
\text { nhạy }\end{array}$ & $\begin{array}{c}\text { Độ đặc } \\
\text { hiệu }\end{array}$ \\
\hline 0,00 & 1,000 & 0,000 \\
\hline 1,50 & 0,847 & 0,643 \\
\hline 2,50 & 0,729 & 0,866 \\
\hline 3,50 & 0,407 & 0,9955 \\
\hline 4,50 & 0,068 & 0,991 \\
\hline 6,00 & 0,000 & 1,000 \\
\hline
\end{tabular}

Nhân xét: Giá trị tiên lượng của thang điểm PAASH với kết cục bất lợi sau 1 tháng là tốt (diện tích dưới đường cong 0.83 , KTC 95\% 0.76 0.90). Điểm cut-off là 2,5 với độ nhạy là 0,729 và độ đặc hiệu 0,866.

Bảng 1.2. Môi liên quan giữa điểm WFNS với mRS = 4- 6 tại thời điểm 1 tháng

\begin{tabular}{|c|c|c|c|c|c|}
\hline & Tân & Tỷ số chênh & \multicolumn{2}{|c|}{ KTC 95\% } & \multirow{2}{*}{ p } \\
\cline { 4 - 5 } & suất & (OR) & Nhỏ nhất & Lớn nhất & \\
\hline WFNS score & 71 & 2,470 & 1,889 & 3,231 & $<0,001$ \\
\hline \multicolumn{7}{|c|}{ Phân loại mức độ nặng theo WFNS: } \\
\hline Độ I & 33 & - & - & - & - \\
\hline Độ II & 6 & 2,958 & 0,769 & 11,379 & 0,115 \\
\hline Độ III & 3 & 2,958 & 0,509 & 17,184 & 0,227 \\
\hline Độ IV & 21 & 12,256 & 4,876 & 30,809 & $<0,001$ \\
\hline Độ V & 8 & 71,000 & 13,749 & 366,632 & $<0,001$ \\
\hline
\end{tabular}

Nhận xét: Mức độ nặng phân loại theo thang điếm WFNS càng tăng thì tỷ lệ gặp kết cục bất lợi tại thời điểm 1 tháng càng lớn.

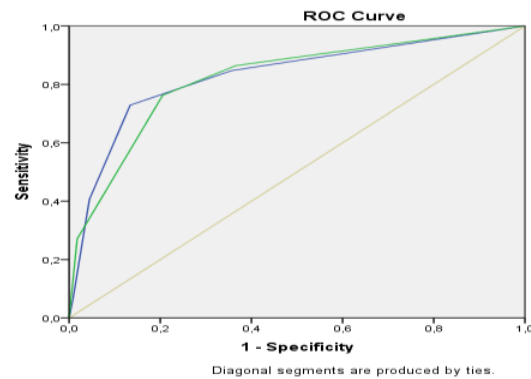

Biêu đồ 1.2. So sánh độ nhạy, độ đặc hiệu của thang điểm PAASH và thang điểm WFNS trong tiên lương kêt cuc chức năng thần kinh bất lợi ( $m R S=4-6$ ) tai thời điêm 1 tháng.

\begin{tabular}{|c|c|c|c|}
\hline \multirow{2}{*}{ Biến số } & $\begin{array}{c}\text { Diến tích } \\
\text { dưới đường } \\
\text { cong }\end{array}$ & \multicolumn{2}{|c|}{ KTC 95\% } \\
\cline { 3 - 4 } & $\begin{array}{c}\text { Nhỏ } \\
\text { nhất }\end{array}$ & $\begin{array}{c}\text { Lớn } \\
\text { nhất }\end{array}$ \\
\hline PAASH & 0,829 & 0,759 & 0,899 \\
\hline WFNS & 0,821 & 0,752 & 0,890 \\
\hline
\end{tabular}

Tọa độ của đường cong WFNS

\begin{tabular}{|c|c|c|}
\hline $\begin{array}{c}\text { Dương tính nếu } \\
\text { lớn hơn giá trị }\end{array}$ & Độ nhạy & Độ đặc hiệu \\
\hline 0,00 & 1,000 & 0,000 \\
\hline 1,50 & 0,847 & 0,643 \\
\hline 2,50 & 0,814 & 0,75 \\
\hline 3,50 & 0,780 & 0,795 \\
\hline 4,50 & 0,271 & 0,982 \\
\hline 6,00 & 0,000 & 1,000 \\
\hline
\end{tabular}

Nhận xét: Giá trị tiên lượng của thang điếm PAASH với kết cục bất lợi sau 1 tháng gân tương đương thang điểm WFNS (diện tích dưới đường cong ROC của PAASH 0.81, KTC 95\% 0.77 0.84 với diện tích dưới đường cong ROC của WFNS 0.82, KTC 95\% $0.78-0.86)$. Thang điểm WFNS có điểm cut-off là 3,5 với độ nhạy là 0,780 và độ đặc hiệu 0,795.

2. Mối liên quan giữa một số yếu tố với kết cục bất lợi tại thời điểm 1 tháng. 
Bảng 2.1. Môí liên quan giữa các yếu tố liên quan với kêt quả chức năng thần kinh: Phân tích hồi quy đa biến

\begin{tabular}{|c|c|c|c|c|c|}
\hline & \multirow{2}{*}{$\begin{array}{c}\text { Đơn } \\
\text { vị }\end{array}$} & \multirow{2}{*}{$\begin{array}{c}\text { Tỷ số chênh } \\
\text { (OR) }\end{array}$} & \multicolumn{2}{|c|}{ KTC 95} & \multirow[b]{2}{*}{ p } \\
\hline & & & Nhỏ nhất & Lớn nhất & \\
\hline \multicolumn{6}{|c|}{ Mức độ tốn thương não theo điếm hôn mê Glasgow: } \\
\hline Nhe (13-15) & $\%$ & - & - & - & - \\
\hline Trung bình (9-12) & $\%$ & 3,650 & 1,126 & 11,832 & 0,031 \\
\hline Nặng (3-8) & $\%$ & 32,465 & 8,599 & 122,567 & $<0,001$ \\
\hline Bế đáy & $\%$ & 4,446 & 1,500 & 13,177 & 0,007 \\
\hline \multicolumn{6}{|l|}{ Điều trị } \\
\hline Không can thiệp điều trị túi phình & $\%$ & - & - & - & - \\
\hline $\begin{array}{l}\text { Can thiệp nội mạch bằng coils gây bít } \\
\text { tắc túi phình }\end{array}$ & $\%$ & 0,078 & 0,015 & 0,396 & 0,002 \\
\hline Phâu thuật kẹp cố túi phình & $\%$ & 0,158 & 0,030 & 0,826 & 0,029 \\
\hline Co thắt mạch và thiếu máu não muộn & $\%$ & 12,185 & 2,981 & 49,802 & 0,001 \\
\hline Constant & & 0,227 & & & 0,078 \\
\hline
\end{tabular}

Nhận xét: Tình trạng nặng của mức độ tổn thương não theo điểm hôn mê Glasgow, tình trạng xuất huyết tại bể đáy, biến chứng co thắt mạch và thiếu máu não muộn là các yếu tố tiên lượng độc lập thuận với kết cục bất lợi. Điều trị can thiệp nội mạch bằng coils gây bít tắc túi phình, phẫu thuật kẹp cổ túi phình là các yếu tố tiên lượng độc lập nghịch với kết cục bất lợi

\section{BÀN LUÂN}

Kết quả nghiên cứu cho thấy tỷ suất chênh (OR) cho kết cục chức năng thần kinh bất lợi tại thời điểm 1 tháng tăng đồng đều với các mức độ nặng của thang điểm PAASH. Đường cong ROC (biểu đồ 1.1) thể hiện giá trị tiên lượng kết cục chức năng thần kinh tại thời điểm 1 tháng của thang điểm PAASH ở mức tốt (diện tích dưới đường cong 0,83, KTC 95\% 0,76-0,89). Giá trị cut-off có ý nghĩa là 2,5 với độ nhạy là 0,729 và độ đặc hiệu 0,866. Nghiên cứu của Annemarie W. van Heuven và các cộng sự cũng cho thấy tỷ suất chênh $(\mathrm{OR})$ cho kết cục chức năng thần kinh bất lợi tại thời điểm 3 tháng tăng đồng đều với các mức độ nặng của thang điểm PAASH, giá trị tiên lượng ở mức tốt (diện tích dưới đường cong ROC 0,81, KTC 95\% 0,77 - 0,84) [3]. Nghiên cứu Raul Anwar Garcia Santos và cộng sự cho thấy giá trị tiên lượng rất tốt của thang điểm PAASH với chức năng thần kinh sau 6 tháng đánh giá bằng thang điểm Glasgow Outcome Scale (GOS) (diện tích dưới đường cong ROC 0,908, KTC 95\% 0,845 - 0,972).

Đường cong ROC thể hiện giá trị tiên lượng kết cục chức năng thần kinh tại thời điểm 1 tháng của thang điểm WFNS ở mức tốt (diện tích dưới đường cong 0,82, KTC 95\% 0,75-0,89), điểm cut-off có ý nghĩa là 3,5 với độ nhạy là 0,780 và độ đặc hiệu 0,795 . Điều này cũng tương tự với giá trị tốt trong việc tiên lượng của thang điểm WFNS cho kết cục chức năng thần kinh tại thời điểm 3 tháng trong nghiên cứu của Annemarie W. van Heuven (diện tích dưới đường cong 0,82, KTC 95\% 0,78-0,86) [2], nghiên cứu và tại thời điểm 12 tháng trong nghiên cứu của Raimund Helbok (diện tích dưới đường cong 0,87, KTC 95\% 0,85-0,89) [3].

Kết quả nghiên cứu cũng cho thây giá trị dự đoán cho kết cục chức năng thần kinh tại thời điểm 1 tháng của thang điểm PAASH so với thang điểm WFNS là gần tương đương (diên tích dưới đường cong của PAASH là 0,83, KTC $95 \%$ $0,76-0,89$ so với diện tích dưới đường cong của WFNS là 0,82 , KTC $95 \% 0,75-0,89$ ). Điều này cũng tương tự với nghiên cứu của Annemarie W. van Heuven trong việc so sánh giá trị dự đoán giữa 2 thang điểm PAASH và WFNS trong việc dự đoán kết cục chức năng thần kinh tại thời điểm 3 tháng (diên tích dưới đường cong ROC của PAASH 0,81, KTC 95\% 0,77 - 0,84 với diện tích dưới đường cong ROC của WFNS 0,82, KTC $95 \% 0,78-0,86)$.

Điều này chứng minh thang điểm PAASH có thể là một lựa chọn tin cậy trong việc tiên lượng về kết cực chức năng thần kinh trong bênh nhân xuất huyết dưới nhện do võ phình động mạch não. Nó là một thang điểm đơn giản, dể lượng giá khi phân loại dựa trên thang điểm Glasgow Coma Scale (GCS) và giảm thiểu những khó khăn và không đồng nhất trong việc đánh giá các khiếm khuyết thần kinh hơn thang điểm WFNS.

\section{KẾT LUÂN}

Thang điểm tiên lượng khi nhập viện của XHDN do phình động mạch (Prognosis on Admission of Aneurysmal Subarachnoid Hemorrhage - PAASH) có giá trị tốt trong việc dự 
đoán kết cục chức năng tại thời điểm 1 tháng sau khởi phát của bệnh nhẩn XHDN do võ phình mạch não, điểm cut-off có ý nghĩa là 2.5.

\section{TÀI LIÊU THAM KHẢO}

1. (1988). Report of World Federation of Neurological Surgeons Committee on a Universal Subarachnoid Hemorrhage Grading Scale. J Neurosurg, 68(6).

2. Surgical Risk as Related to Time of Intervention in the Repair of Intracranial Aneurysms in: Journal of Neurosurgery Volume 28 Issue 1 (1968). $<$ https://thejns.org/view/journals/j- neurosurg/28/1/article-p14.xml>,

accessed: 23/12/2020.

3. van Heuven A.W., Dorhout Mees S.M., Algra A. và công sứ. (2008). Validation of a prognostic subarachnoid hemorrhage grading scale derived directly from the Glasgow Coma Scale. Stroke, 39(4), 1347-1348.

4. Helbok R., Kurtz P., Vibbert M. và cộng sự. (2013). Early neurological deterioration after subarachnoid haemorrhage: risk factors and impact on outcome. J Neurol Neurosurg Psychiatry, 84(3), 266-270.

\title{
TUÂN THỦ ĐIỀU TRI ARV TRÊN BÊNHH NHÂN HIV CÓĐIỀU TRI NGHIỆN CHẤT DẠNG THUỐC PHIÊ̂N BẰNG BUPRENOPHINE/NALOXONE Ở HÀ NộI
}

\author{
Đinh Thị Thanh Thúy ${ }^{1}$, Vũ Minh Anh ${ }^{1}$, Trần Hữu Bình ${ }^{1}$, \\ Todd Korthuis ${ }^{2}$, Phạm Phương Mai' ${ }^{1}$, Lê Minh Giang1
}

TÓM TẮT

Mục tiêu: Mô tả tỷ lệ tuân thủ điều trị ARV và một số yếu tố liên quan trển nhóm bênh nhân điêu trị nghiện chất dạng thuốc phiện (CDTP̉) và điều trị ARV. Phướng pháp: Nghiên cứu can thiêp không có nhóm chứng tại 4 cơ sở điều trị HIV ngoại trú tại Hà Nội từ năm 2016 đến 2019. Tuyển chọn được 136 đối tượng tham gia và theo dõi trong vòng 12 tháng. Tuân thủ điều trị ARV được đo lường bằng thang đoVAS. Phân tích hỗn hợp (mixed-effect model) để xác định các yếu tố liên quan đến tuân thủ điều trị ARV. Kết quả: $96,3 \%$ người tham gia là nam giới với độ tuổi trung bình là $38 \pm 5,8$ tuổi, $43 \%$ có việc làm, $53,7 \%$ có thời gian sử dụng ma túy trên 10 nẳm và $\mathrm{CD} 4$ trung bình là $411 \pm 216 \mathrm{~TB} / \mathrm{mm}^{3}$.Tự ước tính từ $90 \%$ trở lên uống thuốc ARV đúng giờ trong vòng 7 ngày qua qua là $80,6 \%$ tại thời điểm ban đâu, $87 \%$ tại thời điểm 6 tháng và $79,4 \%$ tai thời điểm 12 tháng. Các yếu tố liên quan đến tuân thủ điều trị cho thấy dương tính với morphine ( $\mathrm{OR}=0.24 ; 95 \% \mathrm{KTC}$ : 0.06-0.90), tải lượng vi rút $\mathrm{HIV} \geq 200$ bản sao/mL $(\mathrm{OR}=0.07 ; 95 \%$ KTC: 0.02-0.28) vàtình trạng điêu trị ARV sau khi tham gia nghiên cứu (OR=0,28; 95\%KTC: 0,08 $0,96)$ thì tuân thủ điêuu trị ARV kém hơn. Kết luận: Tỷ lệ đạt ngưỡng tuân thủ điêu trị ARV tương đối tốt sau 12 tháng theo dõi trong nhóm bệnh nhân nhận điêu trị lồng ghép ARV và điều trị nghiện CDTP bằng buprenorphine.

Tư khóa: tuân thủ điều trị ARV, lồng ghép điều trì nghiện chất và điều trị HIV

\footnotetext{
${ }^{1}$ Trường Đại học Y Hà Nội

${ }^{2}$ Trường Đại học Khoa học và Sức khỏe Oregon-Hoa Kỳ Chịu trách nhiệm chính: Đinh Thị Thanh Thúy

Email: dinhthuy@hmu.edu.vn

Ngày nhận bài: 16.11 .2020

Ngày phản biên khoa hoc: 25.12.2020

Ngày duyệt bài: 4.01.2021
}

\section{SUMMARY \\ ARV ADHERENCE AMONG HIV PATIENTS RECEIVING BUPRENORPHINE/NALOXONE TREATMENT IN HANOI}

Aim:This article aims to describe the ARV adherence rate and associated factors in this population. Methods:Conducting quasi-experimental design (no controlled group) at 4 outpatient HIV clinics in Hanoi between 2016 and 2019, 136 participants and followed up within 12 months. ARV adherence was measured by VAS (visual analogue scale). Mixed-effect model was applied to identify factors associated with ARV adherence. Results: $96.3 \%$ of participants were male with mean age $38,8 \pm 5,8$ years, $43 \%$ were employed, $53,7 \%$ used heroin over 10 years and mean CD4 count was $411 \pm 216 \mathrm{~TB} / \mathrm{mm}^{3}$. Self-reported timely ARV pills taking from $90 \%$ or more in the last 7 days is $80.6 \%$ at baseline, $87 \%$ at 6 months and $79.4 \%$ at 12 months. Findings from the mixed-effect model analysis showed that having positive with morphine in the urine test $(\mathrm{OR}=0.24 ; 95 \%$ KTC: $0.06-0.90)$ and HIV viral load $\geq 200$ copies/mL(OR=0.07; 95\% KTC: $0.02-$ 0.28 ) and receiving ARV treatment after participating in the study (OR=0,28; 95\%KTC: $0,08-0,96)$ lead to poor adherence to ARV medication. Conclusion: The percentage of optimal ARV adherence after 12 month follow is relative good among patients receiving both ARV and buprenorphine treatment.

Keywords: ARV adherence, integration buprenorphine/naloxone and HIV treatment,

\section{I. ĐĂT VẤN ĐỀ}

Tiêm chích ma túy là hình thái lây nhiễm HIV chủ yếu trên toàn cầu, tỷ lệ hiện nhiễm HIV trong nhóm tiêm chích ma túy toàn cầu là 12,6\% [1] và tại Việt Nam là $12,78 \%$ [2]. Tiêm chích ma túy tác động tiêu cực đối với tiếp cận và điều 